\title{
Single-Stage Operation for Giant Schwannoma at the Craniocervical Junction with Minimal Laminectomy: A Case Report and Literature Review
}

\author{
Sun Yoon ${ }^{1}$, Hunho Park ${ }^{1}$, Kyu-Sung Lee ${ }^{1}$, Seoung Woo Park ${ }^{2}$, Chang-Ki Hong ${ }^{1,2}$ \\ ${ }^{l}$ Department of Neurosurgery, Gangnam Severance Hospital, Yonsei University College of Medicine, Seoul, \\ ${ }^{2}$ Department of Neurosurgery, Kangwon National University Hospital, Chuncheon, Korea
}

Here we report a single-stage operation we performed on a patient with a large schwannoma that extended from the lower clivus to the cervico-thoracic junction caudally. A number of authors have previously performed multilevel laminectomy to remove giant schwannomas that extend for considerable length. This technique has caused cervical instability such as kyphosis or gooseneck deformity on several occasions. We removed the tumor with a left lateral suboccipital craniectomy with laminectomy only at $\mathrm{C} 1$ and without any subsequent surgery-related neurologic deficits. However, this technique requires meticulous preoperative evaluation on existence of Cerebrospinal fluid (CSF) cleft between the tumor and spinal cord on magnetic resonance imaging, of?tumor origin located at the upper cervical root, and of detachment of tumor from the origin site.

Key Words: Spinal cord neoplasms $\cdot$ Neurilemmoma $\cdot$ Laminectomy $\cdot$ Laminoplasty

\section{INTRODUCTION}

Although schwannomas are the most common primary spinal tumors, schwannomas located at craniocervical junction are rare ${ }^{3,8,9)}$. Intradural spinal schwannomas are usually located at the dorsal or dorsolateral aspect of the spinal $\operatorname{cord}^{4)}$. Anteriorly located craniocervical junction schwannomas with posterior fossa extension are very rare. Here we report a case of a large schwannoma extending from the lower clivus to the cervico-thoracic junction caudally. This is rare and surgically challenging. We describe a patient with a huge craniovertebral schwannoma who was successfully treated with a singlestage operation that consisted of only a C1 laminectomy and a lateral suboccipital craniectomy.

\section{CASE REPORT}

\section{Presentation and Examination}

A 32-year-old woman was transferred to our hospital with posterior neck pain and difficulty walking. She was very slen-

- Received: June 10, 2016 • Revised: July 22, 2016

- Accepted: August 3, 2016

Corresponding Author: Chang-Ki Hong

Department of Neurosurgery, Brain Tumor Clinic, Gangnam Severance Hospital, Yonsei University College of Medicine, 211 Eonju-ro, Gangnam-gu, Seoul 06273, Korea

Tel: +82-2-2019-3391, Fax: +82-2-3461-9229

E-mail: yedamin@yuhs.ac

@This is an open access article distributed under the terms of the Creative Commons Attribution Non-Commercial License (http://creativecommons.org/licenses/by-nc/4.0/) which permits unrestricted non-commercial use, distribution, and reproduction in any medium, provided the original work is properly cited. der and pale. On neurologic examination, she had grade IV spastic quadriparesis and hyperreflexia of all limbs. There was neither past medical history nor any positive neuromuscular marker. Magnetic resonance imaging (MRI) was obtained immediately and showed a huge mass extending from the foramen magnum to the entire cervical spinal canal (Fig. 1). MRI also revealed a small meningioma in the left cerebellopontine angle. The giant tumor was highly enhanced on T1-weighted MRI with contrast and extended from the lower clivus to the C7 level. T2-weighted MRI again showed a huge tumor with hyperintense signal that was severely compressing the spinal cord and displacing it posteriorly. T1 axial MRI images showed widening of the dural sleeve of the $\mathrm{C} 2$ ganglion and tumor extending into the intradural space (Fig. 1). This suggested a possible tumor origin.
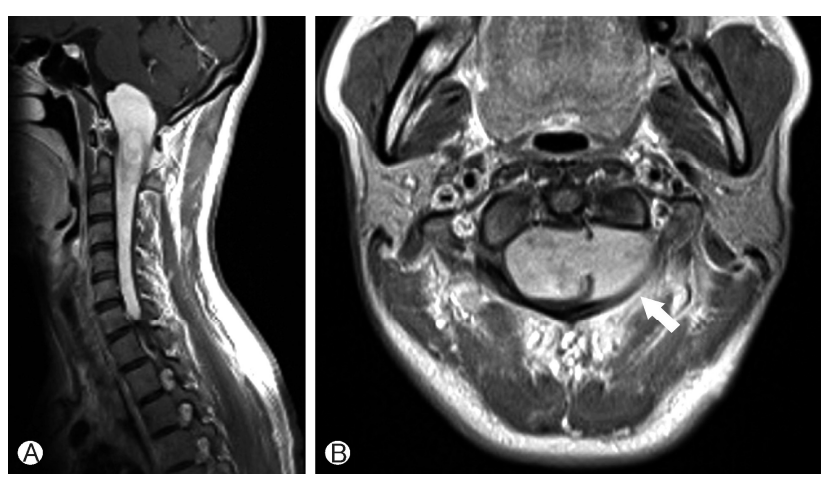

Fig. 1. Sagittal (A) and axial (B) T1-weighted preoperative magnetic resonance imaging showing a homogeneously-enhancing mass (white arrow). The mass is severely compressing the spinal cord posteriorly. The dural entry is widened. 


\section{Operation}

Initially, we planned to operate in conjunction with a spinal surgeon. After general anesthesia, intraoperative monitoring was applied. Closed observation with Somatosensory evoked potential (SSEP) was done while setting the position. The patient was placed in the lateral decubitus position for a left farlateral approach. However the patient's neck was kept straight to protect from compression of the spinal cord and brainstem by the tumor. Skin preparation was performed from behind the ear to the cervico-thoracic junction. At first, a hockey stick skin incision extended from the retroauricular area to the level of the $\mathrm{C} 2$ vertebral body. The posterior neck muscles were dissected layer by layer to identify and protect the vertebral artery. The tumor extended posteriorly into the myofascial planes. We determined that the tumor originated in the C2 dorsal root ganglion (Fig. 2A). The vertebral artery was displaced laterally. The vertebral artery was mobilized laterally after lateral suboccipital craniectomy and C1 laminectomy had been performed. We removed the tumor in the anterior foramen magnum and posterior fossa after cutting the $\mathrm{C} 2$ root of the tumor origin through the left far-lateral corridor. The tumor was soft and the margin was clear and nonadhesive. After removal of the tumor in the posterior fossa with an ultrasonic aspirator, we carefully and gently pulled out the tumor from the spinal canal with tumor forceps. The tumor slipped out of the spinal canal without any resistance. Finally we could remove the rest of the tumor without extension of the laminectomy (Fig. 2). The patient fully recovered during the postoperative period without surgery-related complications.

\section{DISCUSSION}

Schwannomas involving the craniovertebral junction are uncommon. Giant spinal schwannomas located at the ventral midline location are very rare ${ }^{11,15,18-20)}$. Sridhar et al. ${ }^{20)}$ defined

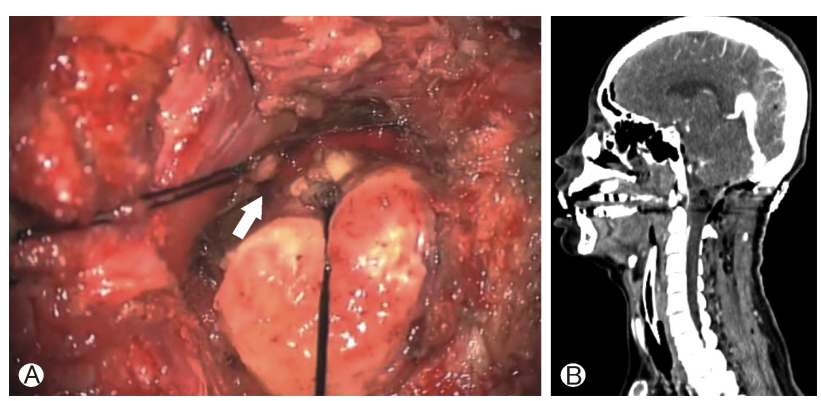

Fig. 2. (A) Operative photograph showing detachment of the tumor from the C2 nerve root (white arrow). (B) Postoperative sagittal computed tomography revealing that the tumor was completely removed with suboccipital craniectomy and C1 laminectomy. The other cervical lamina are intact. giant invasive spinal schwannomas as tumors that extend over more than 2 vertebral levels. The relatively large size of schwannomas at the C1-2 level can be explained by the spacious spinal canal at this level and by a dumbbell-shaped growth pattern with intraspinal-extraspinal extension ${ }^{12)}$. The average sagittal diameters at the levels of the atlas and axis are 23 and $20 \mathrm{~mm}$, respectively, while in the subaxial spine, the average diameter is only $15 \mathrm{~mm}^{5}$. Consequently, clinical symptoms and signs are not present until the tumor enlarges enough to compress neural structures. Surgical removal is the treatment of choice, but is involved. However, Katsumi et al. ${ }^{14)}$ report an incidence of deformity of $20 \%$ for cervical schwannomas and a risk of cervical instability resulting from laminectomies for removal of spinal cord tumors ${ }^{13)}$. Fassett et al. ${ }^{6}$ reported that cervical stenosis after laminectomy is rare in patients with degenerative disease, but more common with intramedullary tumor resections. They also report that a risk factor for cervical deformity is laminotomy for resection of spinal cord tumors ${ }^{6}$. Particularly in children, multilevel laminectomy for intraspinal tumors has a high incidence of spinal deformity ${ }^{2,67,14,17}$. Intramedullary spinal cord tumors can lead to spinal deformities in both adults and children because the tumors involve the anterior horn cells ${ }^{6,17)}$. Another risk is kyphosis after laminectomy, which is highly correlated with removal of facet joints ${ }^{16}$. Inoue et al. report that laminoplasty could be effective in preventing neck deformity after multilevel laminotomy ${ }^{10,14-16)}$. However, Kim et al. ${ }^{15)}$ reported on a case of a huge schwannoma extending from the craniocervical junction to the upper thoracic spine. They removed the schwannoma through multilevel laminoplasty without any surgery-related complications. However, the patient developed postoperative kyphotic deformity three months postoperatively ${ }^{15}$.

In our case, we initially planned a left far-lateral craniectomy combined with a multilevel laminotomy from $\mathrm{C} 1$ to $\mathrm{C} 7$ to expose the entire tumor. After left far-lateral craniectomy with vertebral artery transposition and C1 laminectomy, we began to decompress the tumor. The tumor was very soft and easily sucked up with the ultrasound aspirator. Mahore et al. ${ }^{18)}$ report that giant ventral schwannomas tend to have softer consistency due to extensive ischemic degenerative changes due to the insufficient blood supply that results from their huge size. After detaching the tumor from its origin and removing the cranial part of the tumor, we tried to pull out the tumor gently. The tumor was easily and smoothly pulled out of the canal. We removed the remaining tumor that filled the intraspinal canal without further laminectomy. It is possible to remove the entire giant schwannoma without multilevel laminotomy because spinal cord schwannomas are benign and encapsulated. Schwannomas are easily dissected from the cord because they usually do not infiltrate the spinal cord and are less adhesive ${ }^{1)}$. In this case, the tumor originated at the C2 nerve root and was adherent to the spinal cord. The lower cervical portion of tumor was relatively free in the subarachnoid space.

In giant schwannomas originating from the high cervical 
region, such as from the clivus to the cervicothoracic junction, removal may be performed with only a lateral suboccipital craniectomy and C1 laminectomy. It is not mandatory to perform a removal of multiple levels of cervical lamina. However, this technique might be disastrous without meticulous preoperative MRI evaluation and a gentle surgical procedure. Pulling out the tumor with minimal laminectomy may be tried when there are several factors, including a CSF cleft between the tumor and spinal cord on MRI, a tumor origin located at the upper cervical root, and a tumor that is easily removed after detachment from the origin. It is reckless to try to pull down the tumor without caution. On the contrary, in cases of strong adhesions, as might be expected in neurofibromatosis, it is important to dissect the tumor from the neural structures after fully exposing the entire tumor. Laminoplasty with reconstruction of the nuchal ligament is essential to prevent postoperative cervical instability ${ }^{14,15)}$.

\section{CONCLUSION}

We report on a very rare, large schwannoma located in an anterior cervical position with extension into the posterior fossa. The tumor originating from $\mathrm{C} 2$ nerve root and showing CSF cleft between spinal cord and tumor at MRI was successfully removed with a left lateral suboccipital craniectomy and C1 laminectomy without any neurological deficits.

\section{CONFUCT OF INTEREST}

No potential conflict of interest relevant to this article was reported.

\section{REFERENCES}

1. Ban JY, Oh KS, Shin YG, Kim HK, Rheu TH, Lee JS, et al: Asymtomatic giant benign schwannoma involving cervical vertebral body: a case report. J Korean Neurosurg Soc 28:273-276, 1999

2. Bell DF, Walker JL, O'Connor G, Tibshirani R: Spinal deformity after multiple-level cervical laminectomy in children. Spine (Phila Pa 1976) 19:406-411, 1994

3. Cantore G, Ciappetta P, Delfini R, Vagnozzi R, Nolletti A: Intramedullary spinal neurinomas. Report of two cases. J Neuro- surg 57:143-147, 1982

4. Conti P, Pansini G, Mouchaty H, Capuano C, Conti R: Spinal neurinomas: retrospective analysis and long-term outcome of 179 consecutively operated cases and review of the literature.
Surg Neurol 61:34-43, 2004

5. El-Sissy MH, Mahmoud M: C2 root nerve sheath tumors management. Acta Neurochir (Wien) 155:779-784, 2013

6. Fassett DR, Clark R, Brockmeyer DL, Schmidt MH: Cervical spine deformity associated with resection of spinal cord tumors. Neurosurg Focus 20:E2, 2006

7. Fraser RD, Paterson DC, Simpson DA: Orthopaedic aspects of spinal tumors in children. J Bone Joint Surg Br 59:143-151, 1977

8. Gupta SK, Kumar A, Khosla VK: Giant dumbbell foramen magnum neurinomas presenting as posterior neck masses: singlestage removal by posterior midline approach. Neurol India 55:61-63, 2007

9. Herregodts P, Vloeberghs M, Schmedding E, Goossens A, Stadnik T, D'Haens J: Solitary dorsal intramedullary schwannoma. Case report. J Neurosurg 74:816-820, 1991

10. Inoue A, Ikata T, Katoh S: Spinal deformity following surgery for spinal cord tumors and tumorous lesions: analysis based on an assessment of the spinal functional curve. Spinal Cord 34: 536-542, 1996

11. Jeon JH, Hwang HS, Jeong JH, Park SH, Moon JG, Kim CH: Spinal schwannoma; analysis of 40 cases. J Korean Neurosurg Soc 43:135-138, 2008

12. Kabatas S, Cansever T, Yilmaz C, Demiralay E, Celebi S, Caner $\mathrm{H}$ : Giant craniocervical junction schwannoma involving the hypoglossal nerve: case report. Turk Neurosurg 20:73-76, 2010

13. Kaptain GJ, Simmons NE, Replogle RE, Pobereskin L: Incidence and outcome of kyphotic deformity following laminectomy for cervical spondylotic myelopathy. J Neurosurg 93(2 Suppl):199204, 2000

14. Katsumi Y, Honma T, Nakamura T: Analysis of cervical instability resulting from laminectomies for removal of spinal cord tumor. Spine (Phila Pa 1976) 14:1171-1176, 1989

15. Kim SH, Doh JW, Yoon SM, Yun IG: Huge schwannoma extended from craniocervical junction to upper thoracic spine. J Korean Neurosurg Soc 34:589-592, 2003

16. Lonstein JE: Post-laminectomy kyphosis. Clin Orthop Relat Res (128):93-100, 1997

17. Lunardi P, Licastro G, Missori P, Ferrante L, Fortuna A: Management of intramedullary tumours in children. Acta Neurochir (Wien) 120:59-65, 1993

18. Mahore A, Chagla A, Goel A: Giant ventral midline schwannoma of cervical spine: agonies and nuances. J Korean Neurosurg Soc 47:454-457, 2010

19. Nagasawa S, Ohta T, Kajimoto Y, Aoki J, Onomura T, Miyaji Y: Giant neurinoma occupying the holocervical and upper thoracic regions: case report. Surg Neurol 42:157-159, 1994

20. Sridhar K, Ramamurthi R, Vasudevan MC, Ramamurthi B: Giant invasive spinal schwannomas: definition and surgical management. J Neurosurg 94(2 Suppl):210-215, 2001 